\title{
EL OBSCENO PAJARO DE LA NOCHE: LA PRODUCTIVIDAD DEL TEXTO
}

En el espacio del texto de El obsceno pájaro de la noche ${ }^{1}$ juega un metatexto que habla una poética de la ficción. En efecto, las innumerables historias que mutándose infinitamente recorren el lugar sin límites del discurso donosiano, encubren y descubren la «historia» de su escritura. Haciéndose eco del texto cervantino, el de Donoso habla postulando -o postula hablando- su propia creación.

Aun cuando la novelística donosiana se presta a múltiples enfoques interpretativos, creemos que un examen cabal de la misma (al menos de $E O P N$ ) impone su inserción en el contexto de especulaciones críticas de avanzada, tales como las emitidas por algunos de los miembros del grupo «Tel Quel». Hemos tenido en cuenta, particularmente, los estudios post-estructuralistas de Jacques Derrida ${ }^{2}$. De hecho, la praxis de infinita

1 José Donoso, El obsceno pájaro de la noche (Barcelona: Seix Barral, 1970). Otras obras del autor: Cuentos (Barcelona: Seix Barral): este volumen reúne las historias incluidas en Veraneo y otros cuentos (1955) y El Charleston (1960), Coronación (1958), Este domingo (1966), El lugar sin limites (1967), Tres novelitas burguesas (1973). Donoso ha escrito además una Historia personal del «boom» (Barcelona: Anagrama, 1972). Y acaba de aparecer una nueva novela, Casa de campo (Barcelona: Seix Barral, 1978). Las referencias futuras a El obsceno pájaro de la noche se indicarán mediante las siglas EOPN. Las páginas correspondientes a citas futuras se incluirán en el texto.

${ }^{2}$ Obras de Jacques Derrida: Introduction à l'origine de la géometrie (1962); La voix et le phénomène (Presses Universitaires de France, 1967; traducción inglesa, Speech and Phenomena, Evanston, U.S. A.: Northwest University Press, 1973, realizada por David B. Allison); De la grammatologie (Paris: Minuit, 1967; traducción española con una excelente introducción de Phillipe Sollers, De la gramatología, Buenos Aires: Siglo XXI, 1971, realizada por Del Barco y Ceretti); L'écriture et la différence (Paris: Seuil, 1967); La dissémination (Paris: Seuil, 1972; traducción española, La diseminación, Madrid: Fundamentos, 1975, realizada por José Martín Arancibia). Hemos consultado además la antología Théorie d'ensemble (Paris: Setill, 1968), donde figura el artículo de Derriba sobre «La différance» (traducción española, Teoría de conjunto, Barcelona: Seix Barral, 1971, 
mutación que descentraliza el espacio del texto de EOPN actualiza el presupuesto axial del aparato conceptual de Derrida: la descentralización del logocéntrico ${ }^{3}$ discurso de Occidente y la derrota de la presencia que lo organiza: presencia o subjetividad presente en sí que es, simultáneamente, pre-sentido. Descentralizado, el discurso deviene un juego de sustituciones infinitas.

Sin embargo, la problemática de la descentralización del discurso revela otra fuente teórica de interés: los estudios estructuralistas sobre el carnaval, el diálogo y la polifonía realizados por M. M. Bajtin y sus seguidores en los años veinte ${ }^{4}$. Precisamente estos trabajos fundamentan, siquiera parcialmente, las teorizaciones de algunos de los miembros del grupo «Tel Quel» sobre la novelística actual. Por razones de claridad, sin embargo, preferimos hablar de desplazamiento del centro, no de auténtica descentralización en lo que atañe a los postulados de Bajtin.

A partir de sus especulaciones sobre la polifonía - y en base a un análisis exhaustivo de la novelística de Dostoievski-, Bajtin postula un texto ficcional plenamente dialogizado: espacio de confrontación de las diversas voces que encarnan las diversas subjetividades enfrentadas ${ }^{5}$. En

pp. 49-95, realizada por Oliva y Oller). El mismo artículo figura en el texto inglés Speech and Phenomena. Otra antología de interés, en tanto reúne textos de Sollers, Barthes, Henric y Guyotat pertinentes a nuestro tema figura bajo el título de Literatura, política y cambio (Buenos Aires: Calden, 1976; trad. Alberto Drazul).

${ }^{3}$ Se entienda la noción de Logos como razón o principio estructurante del universo (que se encarna en la "phoné»), o como espíritu divino que crea y sostiene el cosmos; el Logos entraña no sólo un centro (que es principio y final), sino también la presencia trascendente o subjetividad que justifica y ordena racionalmente el universo. Tanto la subjetividad creadora infinita (Dios) como la subjetividad o razón humana (un reflejo de aquélla) revelan el carácter ontoteológico de la episteme occidental y postulan la metafísica de la presencia, presencia que es pre-sentido y que sostiene el discurso logocéntrico.

${ }^{4}$ Hemos consultado las siguientes obras de M. M. Bajtin: $L a$ Poétique de Dostoievski (Paris: Éditions du Seuil, 1970; hay versión inglesa, Problems of Dostoievsky's Poetics, EE. UU.: Ardis, 1973; el original ruso fue publicado en Leningrado, 1929); Rabelais and his World (Cambridge, Mass.: M. I. T., 1968; hay versiones francesa y española; el original ruso fue publicado en Moscú, 1965); «L'énoncé dans le roman» (Langages, 12, 1968), pp. 126-32; «Epopée et roman» (Recherches internationales à la lumière du marxisme, 76, 1973), pp. 1-39; "Le verbe dans le roman» (Sciences sociales, Moscú, núm. 1, 31, 1978), pp. 141-154.

${ }^{5}$ Bajtin y los miembros de su grupo fueron los primeros estudiosos en tomar conciencia cabal del papel del emisor del acto de habla, superando de este modo la etapa saussureana del énfasis en el sistema de la lengua y en lo social (a expensas de lo individual). Emanado de una subjetividad que, en mayor o menor grado, centraliza o desquicia el discurso en que se encarna, el hecho del habla (parole) -o discurso personal, en palabras de Emile Benveniste - se convierte en el eje de las investigaciones linguiísticas y literarias de nuestra época. 
este espacio, el personaje se postula como conciencia problematizada por la presencia de «el otro» ${ }^{6}$; como subjetividad que se desgarra al ser arrebatada por una decisiva confrontación consigo misma (su «otro yo»), con «los otros» y con «lo otro» (Dios, la historia, sus circunstancias). De este modo, la subjetividad se encarna no en una enunciación univocal en la que una voz central acalla a las demás, sino, por el contrario, en un discurso multivocal o polifónico en el que diversas voces -la del emisor y la(s) de su(s) destinatario(s) se comprometen en un diálogo sin acabamiento ni solución. Este discurso polifónico -espacio en el que nadie, ni siquiera el autor «real» de la ficción, tiene la última palabraescamotea un auténtico centro de significación, ya que éste (el centro falaz) se desplaza sin cesar, comprometido como está en una suerte de vaivén que señala, sucesivamente, las diversas posturas ideológicas que encarnan las diversas voces. En oposición a la ficción monológica tradicional, en la que una voz unificadora silencia a las otras e impone un centro único de significación, la polifonía se exhibe como estructura abierta, espacio que despliega diversas ideologías, aunque sin institucionalizar ninguna. Diversas ideologías que, sin embargo, hablan un presentido o significado trascendente del cual las voces actualizan sólo algunas de sus infinitas posibilidades de interpretación. En otras palabras: el planteamiento de Bajtin sobre la polifonía se mantiene dentro de los límites de la metafísica de la presencia y, por tanto, en el contexto de nuestro raigal logocentrismo.

En concreto, mientras el esquema de Bajtin pauta la operación del desplazamiento del centro que engendra la polifonía, el de Derrida postula la dinámica de la descentralización que genera el juego de las sustituciones infinitas. En última instancia, sin embargo, la multivocalidad que instrumenta el texto de Donoso pone en marcha lo que podríamos rotular la polifonía de la descentralización: si el desplazamiento del centro entraña la confrontación dialógica de las diversas posibilidades de interpretación de un significado anterior al discurso, la polifonía de la descentralización encarna el juego de la postergación infinita de un significado que es siempre «otro», que es por siempre diferido. En el espacio de EOPN una voz se muta en otra, y ésta en otra, y ésta en otra: irre-

${ }^{6}$ Las varias voces que encarnan las diversas subjetividades en conflicto instauran el diálogo en el plano personal (subjetivo o intersubjetivo) del discurso. Al nivel transpersonal las voces representan no subjetividades, sino diversos estilos literarios confrontados y comprometidos en la praxis dialógica que fundamenta la bivocalidad y la polifonía. Para un detallado examen de los presupuestos teóricos de M. M. Bajtin sobre la polifonía en la ficción, véase nuestro artículo «El carnaval, el diálogo y la novela polifónica» (Hispamérica, año VI, núm. 17, 1977). 
sistible travestismo que acaba nulificando la praxis polifónica y silenciando irrevocablemente el personaje: silenciamiento equiparable a una claudicación definitiva. Todo ello justifica las implicaciones, sostenidas a lo largo de $E O P N$, de un niño milagroso, un paródico Cristo al revés: mientras el Cristo es Palabra que da vida, Humberto encarna el silencio que es la muerte.

Anteriormente a «silenciarse», sin embargo, Humberto ha «enmudecido». Si el silencio constituye la culminación de su infernal odisea, un enmudecimiento previo señala el punto de partida de su vertiginosa carrera hacia la nada. En este contexto, enmudecer debe entenderse como la clausura total del dialogar del personaje con «el otro». En efecto, aun cuando el Humberto que habla el texto de $E O P N$ se exhibe como subjetividad ya descentralizada en tanto ha acallado el diálogo, es dable suponer que en una época pretérita Humberto Peñaloza cabalmente dialogó. En esa hipotética etapa, Humberto se reconoce como Humberto. Vivencia su identidad personal al vivenciarse como subjetividad - como centro- desde el cual organiza su experiencia y su discurso: como subjetividad que, instalada en el espacio de la interacción (intersubjetividad) humana, se sale de sí para encontrar, dialógicamente, a «el otro». Al ser reconocido por éste, Humberto se reconoce a sí mismo: la subjetividad (la palabra) de «el otro» le devuelve, como un espejo una imagen, la certeza de su propia realidad.

A la larga, sin embargo, Humberto Peñaloza intuye que tal reconocimiento ha sido una ilusión, constatación que lo arroja a la penumbra del mundo de los seres desposeídos de rostro, de nombre, de realidad. No reconocido por «el otro», Humberto acaba des-conociéndose a sí mismo: distanciándose (extrañándose) no solamente de aquél, sino fundamentalmente de sí. Más aún, al vaciarse de sí mismo, Humberto, a su vez, vacía a «el otro», lo despersonaliza, lo descentraliza. Descentralizadas (desrealizadas), ambas entidades se convierten en simulacros de presencia, en «no personas» ${ }^{7}$ que juegan el juego interminable de la sustitución. Juego de un espacio sin centro: vasto escenario - terreno de todos y tierra de nadie - en el que proliferan máscaras que fugazmente enmascaran el terror a la anulación definitiva. Vertiginoso espacio de una enunciación en la que Humberto contempla, como en un abismal y deformante espejo, la fuga eterna de su escamoteada identidad. Humberto se contempla alterado: subjetividad que se diluye en una serie infi-

\footnotetext{
"Para un cabal entendimiento de la noción de «no persona», consultar el trabajo de Émile Benveniste «L'homme dans la langue», en Problèmes de linguistique générale (Paris: Gallimard, 1966), tomo I, pp. 225-285.
} 
nita de falaces «otridades». Por tanto, una díada primera, Humberto/ Mudito - hipóstasis de un "yo» original afantasmado y, simultáneamente, dos versiones opuestas del escritor- pone en marcha el juego de la escritura de EOPN. El discurso de Humberto -un Humberto que es Mudito y un número infinito de «otridades»- encarna la derrota de la presencia y la consecuente descentralización que postula Derrida.

En concreto, mientras el esquema de Bajtin propone el desplazamiento de un centro - un centro cabalmente falaz - que engendra la polifonía (repetimos, la confrontación dialógica de las infinitas posibilidades de interpretación de un significado anterior al discurso), el esquema derridiano pauta la polifonía de la descentralización. Esta señala la derrota del Logos - Logos que apunta a un significado trascendente o presentido- e impone el juego de un sentido por siempre diferente y por siempre diferido. (Juego que habla de la «différance» derridiana, a la cual retornaremos.) Superando los límites lingüísticos, literarios e ideológicos del esquema de Bajtin, Derrida toca el terreno de la metafísica y proclama la clausura de la episteme occidental. Iconoclasta cabal - hermanado a aquel otro iconoclasta que fue Nietzsche-, Derrida anuncia el ocaso de la razón ordenadora (el Logos, la presencia) y proclama el advenimiento del juego. Juego de un discurso que desplegándose como perpetuo devenir apunta a un sentido por siempre postergado; siempre "otro", perennemente alterado ${ }^{8}$. Comprometido en un proceso de vertiginosa alteridad.

En concreto, la problematización del personaje confrontado con «el otro» del esquema de Bajtin (Humberto Peñaloza ante sí mismo y ante su realidad) se transforma en la problematizada confrontación del personaje con el juego de su devastadora alteridad ${ }^{9}$ : juego de la sustitución

${ }^{s}$ En el proceso de significación que erige el discurso tradicional coinciden dos operaciones complementarias. Se da, por un lado, la puesta en relación del significante y el significado; por el otro, la del significado con los otros significados en el interior de un sistema, espacio en que los signos circulan preservando los sentidos tradicionales. En el discurso descentralizado, por el contrario, el significante no denota un significado (que se relacione con otro significado), sino un significado que excede al significante y lo desborda, para acabar borrando los límites del espacio en que se mueven los sentidos tranquilizadores. Desborde y borradura relacionados con el juego de la «alteridad», la cual, a su vez, entraña una perenne virtualidad.

9 Adoptamos los términos alteridad y otridad como sinónimos. Sin embargo, mientras el primero señala todo un proceso -el de una sustitución infinita-, el segundo alude a los infinitos y fugaces estadios que actualizan tal proceso de sustitución. Identificamos, además, las ideas de alteridad y de otridad con la de «la realidad otra», concepto que, similarmente, denota "el otro lado" o revés de lo establecido: en suma, el inconsciente. Ninguna de estas nociones debe confundirse, 
infinita de posibles «otridades» en las que Humberto sólo esporádica y fugazmente se reconoce como Humberto. Siguiendo a Freud, entendemos la noción de alteridad como el «otro lado» o el revés de la conciencia (de esa conciencia que organiza no sólo la identidad personal, sino también la identidad de «el otro» y que ordena, además, nuestra gramática, nuestra historia y nuestra metafísica). Alteridad entendida, en suma, como inconsciencia. Des-cubierta su alteridad, la subjetividad se descentraliza y precipita en el abismo de las infinitas posibilidades virtuales en el ser, para ser finalmente arrebatada por un irrefrenable juego de diferencias y diferimientos que la afantasman. (Diferencias y diferimientos que actualizan el juego de la «différance»). En última instancia, la fantasmal entidad deja de ser presencia, sin por ello, sin embargo, instituirse como ausencia. Diferir una presencia implica postergar también su ausencia.

$\mathrm{Ni}$ presencia ni ausencia, por tanto. Sólo perenne alteridad: suerte de indiferenciación primordial cuya dinámica arroja al protagonista a un vertiginoso escenario donde actúa y re-actúa todas sus posibilidades. Ese escenario no es sino el discurso descentralizado en el que un significado desbordante actúa y re-actúa su inagotable virtualidad: espacio sin límites en que el discurso juega su práctica textual o productividad, o sea, el diferimiento infinito de su significación. En efecto, $E O P N$, escritura desposeída de una subjetividad central que la organice, derrota la noción tradicional de «obra» para imponerse en tanto «texto como productividad». De ello se hacen eco las palabras de Derrida: «La destrucción del libro descubre la superficie del texto» ${ }^{10}$.

Oponiendo la noción de "obra» a la de «texto», ciertos sectores de la crítica contemporánea definen a éste como productividad: productividad de una escritura ${ }^{11}$ cuyo sentido no se postula a priori (desde una presencia que es, simultáneamente, pre-sentido), sino que se opera (se produce) simultáneamente al despliegue o juego de su práctica significante (o práctica textual). Juego de un significado eternamente postergado, siempre «otro», nunca cabalmente postulado: «Sentido suspendido, interrogado, diferido ... (que) ... traza la escena de las transformaciones significantes hablando en un espacio múltiple, activo, infinito» ${ }^{12}$. Signi-

sin embargo, con la de «el otro» (y «lo otro»), vale decir con la del «tú» receptor, comprometido en relación dialógica con el «yo» emisor en el circuito de la comunicación.

${ }^{10}$ Derrida, De la gramatología, p. 25.

1 Usamos el término «escritura» como sinónimo de texto o práctica textual.

${ }^{12}$ Phillipe Sollers, «La escritura, función de transformación social», Literatura, política y cambio, p. 122. 
ficado perennemente alterado que se desconstruye y reconstruye ad infinitum.

$E O P N$, práctica textual que derrota no sólo la noción tradicional de «libro» u «obra», sino también la de «autor», encarna en su mismo espacio las antinomias -libro/texto, personalización autorial/despersonalización - cuya desconstrucción ocupa a Donoso. El hipotético libro de lomo verde ${ }^{13}$ (incorporado en EOPN) que Humberto Peñaloza pudo haber escrito en la época en que aún dialogaba con el mundo y en el que narra la idealizada historia de su patrón, don Jerónimo de Azcoitía, representa la obra tradicional, el «libro», específicamente la ficción por excelencia realista que Donoso pone en tela de juicio: discurso logocéntrico, portador de un sentido (o de sentidos) que lo vertebran y organizan en tanto emanan de una subjetividad que es presencia consciente e idéntica a sí misma. Por el contrario, la novela total -el discurso de Mudito, cuya superficie acoge la enunciación de Humberto- encarna el texto: discurso descentralizado en cuyo espacio juega su juego de mutaciones infinitas la enunciación, nacida de la pulverizada subjetividad del hipotético narrador. Subjetividad que si bien no conforma una presencia (como en la instancia del libro de Humberto), tampoco, sin embargo, pauta una ausencia en tanto que su dislocamiento - el desencadenamiento de su alteridad - instaura una perenne virtualidad. Virtualidad que dinamiza la superficie del texto inscribiendo en ella el juego de una múltiple productividad.

La noción de alteridad, ya lo dijimos, conforma uno de los términos de la diada que pone en marcha la dinámica de la «différance» ${ }^{14}$, magistralmente expuesta por Derrida y aplicable sin retaceos al espacio del texto de EOPN. La creación de esta entidad (que no es ni palabra ni concepto, según lo aclara el crítico), y en la cual una letra «a» muda (sólo reconocible en la página escrita) altera la escritura del vocablo "différence», provee a Derrida con una cabal herramienta de trabajo para explicitar, siquiera parcialmente, su propuesta sobre la clausura de la episteme occidental. Apelando a la etimología latina del vocablo

13 Trozos del libro que supuestamente escribió Humberto Peñaloza aparecen esporádicamente a lo largo de $E O P N$. En su mayoría, los ordenados discursos emanados de una omnisciencia tradicional que reaparecen repetidamente pueden considerarse páginas del libro del protagonista. Claramente, el prólogo a su novela sobre don Jerónimo cubre el espacio comprendido entre las páginas 161-165.

${ }^{14}$ Véase Derrida, "La différance», Teoría de conjunto, pp. 49-79. Derrida nota que tanto Nietzsche como Freud «han interrogado la conciencia en la certeza de sí misma»; luego agrega: "¿Acaso no es notable que ambos lo hayan hecho a partir del motivo de la "différance'?s (p. 66). Más aún, Derrida nos recuerda que Freud llama al inconsciente «alteridad». 
— «differre»-, Derrida señala la bisemia entrañada en el mismo. La «différance» indica, por un lado, la noción del diferimiento del significado último de un texto al ser aquél (el significado) arrebatado por la praxis de una infinita postergación; denota, por el otro, la alteridad, o sea, la sucesión de diferencias de significado (de diferentes significados) o de trazos (el término es de Freud) que instauran (o «trazan») el juego de la infinita mutación que es el texto: juego de difiere la resolución del elusivo significado y que instaura la productividad.

En última instancia, la productividad (igualmente explicitada como intertextualidad) debe examinarse en su doble proyección. Se hace patente, por un lado, la productividad inmanente, o sea, el juego de las voces que recorren el espacio de un texto particular (EOPN, por ejemplo); de éstas provienen los consecutivos y efímeros trazos que despliegan (o «trazan») el gráfico de un significado siempre alterado, por siempre postergado. Se da, por otro lado, la intertextualidad o productividad relacional, que va más allá del texto particular y lo vincula con las otras prácticas textuales de una tradición cultural. En esta instancia, el texto mismo deviene el efímero trazo de la escritura plural que nace de la confrontación e interpenetración de todos los textos culturales de tal tradición: escritura que, similarmente, escribe la postergación infinita de su significación. Más aún, la operación productora de significación por la que el texto se desconstruye y reconstruye infinitamente (en su inmanencia y en su trascendencia) compromete, además, al supuesto autor. En efecto, a la par que invalida la noción de «obra» para validar la de texto como productividad, EOPN derrota el concepto de «autor» ${ }^{15}$ en tanto presencia que organiza definitivamente el texto: la puesta en escena de toda una productividad (inmanente y relacional o trascendente) convierte la superficie del texto en escritura en blanco: en tierra de todos y terreno de nadie.

De este modo se pauta la operación de un discurso que se re-escribe en la instancia de cada re-lectura, operación que culmina con la despersonalización del autor «real» y su disolución en las máscaras infinitas de los infinitos lectores o usuarios de los textos. Ello sugiere, simultáneamente, una radicalización del concepto de «lector». Derrotada la praxis representativa/expresiva de la comunicación tradicional, se nulifica la relación tradicional emisor/destinatario para imponerse la de escritura/lectura, vale decir, la de dos productividades coincidentes que,

${ }^{15} \mathrm{Al}$ hablar de la despersonalización del autor, indicamos al autor «real» de la ficción. Llegado el caso, sin embargo, tal despersonalización implica al autor del discurso novelístico: al narrador. 
al coincidir, instauran un espacio. A la larga, ambas entidades (el autor y el lector) devienen simulacros de presencia, «trazos» cabales en el juego de la productividad (inmanente y relacional) de un texto: en el juego de una escritura simultáneamente individual (el texto particular) y plural (la interrelación de todos los textos de una tradición). «El trazo -escribe Derrida- no es presencia, sino el simulacro de una presencia que se disloca, desplaza, aparta y acaba por no producirse» ${ }^{16}$. Simulacro de una presencia comprometida en un proceso de vertiginosa productividad.

En concreto, la pulverizada subjetividad del protagonista - un Humberto que al truncar el diálogo enmudece dejándose arrebatar por su alteridad- pone en marcha la práctica textual de EOPN. El juego especular por el que un fantasmal Humberto se contempla en el espejo deformante de su subjetividad - de su discurso- engendra el texto: escenario sin límites en el cual el narrador se exhibe como un juego infinito de diferencias y de diferimientos. «El subconsciente se difiere», escribe Derrida, «y ello quiere decir ... que se teje de diferencias y también que envía, delega unos representantes o unos mandatarios; pero no hay ninguna oportunidad para que, quien manda, esté presente, exista, sea 'él mismo' en alguna parte y todavía menos que se convierta en consciente» ${ }^{17}$. El subconsciente (Humberto y/o Mudito y/o todos los otros) «se difiere» escribiéndose, desbordando la superficie del texto, borrando los sentidos tranquilizadores, re-escribiéndose: delegándose en signos («trazos») fugaces, en máscaras que momentáneamente enmascaran la esencial irracionalidad del revés de nuestra realidad. Irracionalidad: noción medular que organiza, desorganizando, el mutante escenario donosiano.

Al poner en tela de juicio las nociones tradicionales de "obra» y de «autor» y al exaltar la concepción de «texto como productividad», Donoso simultáneamente enjuicia toda una cultura logocéntrica que, bajo la máscara falaz de Apolo, ha creído subyugar al Dionisio insoslayable. Haciéndonos eco de la "différance» derridiana, EOPN se exhibe como conato por despedazar la reificada imagen del hombre, desconstruir su ilusoria integridad, hacer temblar sus rígidos patrones. Carnavalescamente, Donoso descubre el mundo al revés y hace hablar a la irracionalidad: cháchara obscena del pájaro nocturno, eterna recurrencia de brujeriles voces - descentralizadas y descentralizantes- que si bien acallan el diálogo individual (despersonalizando al autor «real» o bien al hipotético narrador o autor del discurso ficcional), sustentan, sin embargo, el diá-

${ }^{16}$ Derrida, op. cit., p. 75.

${ }^{17}$ Ibíd., p. 70. 
logo de la raza, o sea, la intertextualidad o productividad de la escritura plural de nuestra tradición.

En última instancia, ya lo dijimos, EOPN habla una poética de la ficción: no es accidental que tanto Mudito como Humberto encarnen al escritor. Al mero escritorzuelo de ficciones realistas, el segundo; el primero, al auténtico fabulador: a la bruja cuya voz obsesivamente traduce las voces obscenas de la irracionalidad.

EOPN abre en la Casa de la Encarnación de la Chimba, laberíntica estructura en deterioro habitada por algunas huerfanitas, una que otra monja y por un grupo de ancianas decrépitas y balbuceantes. Viejas, meicas, curanderas, brujas: las borrosas figuras que, infinitamente multiplicadas, acabarán colmando el ámbito de la Casa, encarnan el caos subyacente: la «realidad otra» o «alteridad» que habla por sus bocas develando la cháchara obscena de la irracionalidad. Mudito - asilado en la Casa y transformado él mismo en vieja y bruja fabuladora- es quien recoge las nocturnas voces y las traduce en escritura: vertiginoso juego de signos transformantes y transformables que, liberando espacio, dan cuenta de la descentralización del personaje. Mudito - la «realidad otra» de Humberto Peñaloza y punto de arranque de una irresistible alteridad- encarna al escritor ideal, al hechicero que cerrando los ojos al mundo cotidiano los abre al escondido mundo «otro», al espejo deformante de la irracionalidad. La imagen que el espejo le devuelve -una incontrolable sucesión de máscaras falaces en las que, sin embargo, se reconoce esporádicamente - despedaza definitivamente su identidad y lo arroja en la penumbra de un mundo interno, caótico y fluido - "vago crepúsculo de conciencia» (p. 272) -, en el que por ser todos los otros, termina siendo nadie. Para rescatarse, Mudito/Humberto habla su abismo; lo difiere nombrándolo, nombrándose. Vertiginosamente se enuncia, se escribe, se lee. Narcisísticamente se contempla, se reconoce y desconoce en el espejo, igualmente deformante, de su enunciación.

De hecho, el mundo de José Donoso se inaugura en el instante en que la criatura humana reitera el gesto del mítico Narciso y se contempla en el espejo de una fuente. En el escenario donosiano, sin embargo, alguièn arroja «una piedra insidiosa al espejo del agua» (p. 504), la cual triza la imagen, la deforma y contorsiona, revelando una inmanente y monstruosa alteridad. Este proceso de alteración que sufre el hombre descubre la inminencia del aterrador espectáculo que despliega las infinitas posibilidades virtuales en su ser. El terror, sin embargo, nace no de la resultante proliferación de identidades, sino de la intuición del abismo en que pueden disolverse; en suma, de la «concientización» de la 
nada subyacente. Mudito/Humberto habla su abismo en el afán desesperado de exorcizar la nada; nombra su terror para enmascararlo. A la larga, el pavor del desgarrado personaje se encarna en el espacio de un discurso desmesurado que evoca la imagen de las gárgolas recurrentes en $E O P N$ : «encarnaciones del miedo, sordas, mudas, quizá ciegas, agentes del vacío, del pánico que prefiere retorcerse y transformarse en monstruo antes de no ser nada» (pp. 318-19). Bien entendida, la máscara que enmascara el miedo es monstruosa.

La figura del hombre que se mira en el espejo y queda hechizado o enloquecido al develar su abismo interno se insinúa ya en Coronación ${ }^{18}$, la primera novela de Donoso. Amparado en un «yo» que imaginó inviolable, el protagonista, Andrés Abalos, se ve forzado a contemplar su trizada imagen en «el espejo deformante» de las «palabras de loca» (p. 72) de su abuela. La impúdica charla de la anciana derrumba los rígidos discursos con que Andrés vanamente se afanó por exorcizar el terror de su existencia. Por su parte, misia Elisa Abalos prefigura la hembra aterradora - la arquetípica Peta Ponce- que rige el mundo donosiano. Loca o bruja (para el caso es lo mismo), la vieja es portavoz del mundo recóndito que el espejo devuelve. Mundo al revés, caótico e indiferenciado; fluido y mutante, mundo perennemente "otro». La imagen de la anciana se identifica, además, con la de la bruja que, frente al fuego y a la olla, revuelve caldos mágicos cuyos vapores engendran seres monstruosos. El mutante espacio del habla de las viejas - sustentado por los interminables «dicen» y «dicen que dicen» que recorren la superficie del texto de $E O P N$ - se equipara con el ámbito fluido en que los vapores insinúan los rostros sucesivos del monstruo recóndito.

Es como bruja fabuladora, ya lo postulamos previamente, como $\mathrm{Mu}$ dito/Humberto asume su papel de escritor: «Con el vapor voy urdiendo algo nacido de la libertad anárquica con que funcionan las mentes de las viejas, de las que soy una» (p. 138). Sin embargo, el hechicero es, simultáneamente, hechizado por los poderes que ha convocado: «Era un mundo sellado, ahogante, como vivir dentro de un saco, tratando de morder el yute para ... ver si era afuera o adentro ... donde comenzaba a ser él y dejaba de ser los demás» (p. 244). Se señala, por un lado, la transformación en imbuche ${ }^{19}$ de Humberto; se alude, por el otro, a la

${ }^{18}$ Coronación (Barcelona: Seix Barral, 1971). Las páginas indicativas de citas futuras se incluirán en el texto.

${ }^{19}$ De acuerdo a la tradición chilota (del sur de Chile), el «imbuche» o «machucho», "no es otra cosa que un niño, hijo de brujos, entregado apenas nacido a la colectividad por su propio padre ... (niño a quien se cría) ... enteramente desnudo y con impedimento absoluto de escuchar la voz humanai (Evaristo Moli- 
infinita proliferación de identidades - de máscaras- en que se desdobla y multiplica la subjetividad del narrador. El enajenante imbuchismo to arroja a un abismo donde sucesivamente encarna todos y cada uno de los personajes que su desaforada imaginación convoca. Cuanto más se cancela la realidad externa, más se expande el ámbito interior: «Tapiando y clausurando se agranda, no se restringe, el ámbito de la Casa» (p. 373).

De hecho, la laberíntica Casa de la Encarnación de la Chimba, así como el paraíso de monstruos en que se metamorfosea el fundo de la Rinconada, conforman acertadas metáforas de la enunciación; de la novela total. Ni la Casa ni el fundo señalan una realidad objetiva, ya que la praxis cabalmente representativa está ausente de ese espacio transgresivo en que se desconstruye y reconstruye el discurso de Mudito/ Humberto. Su misma referencialidad - la inserción del personaje en la circunstancia concreta de un tiempo, de un espacio y de un orden establecido y reconocible en el mundo real- queda, asimismo, derrotada. El escritor sólo es su enunciación: enunciación de una conciencia destrozada que, momentáneamente, sobrevive nombrando su abismo, nombrándose; que momentáneamente se difiere tejiéndose de diferencias, delegándose en las máscaras fugaces que enmascaran el terror de no ser. A1 igual que el arquetípico hechicero - para quien el nombre es la cosa y nombrarla significa convocarla y poseerla-, Mudito/Humberto se nombra para sobrevivirse, para conjurar la esencial nadería de nuestra condición.

Es ésta, en concreto, la misión del auténtico escritor, del cabal fabulador. Donoso invalida el fútil conato del creador de ficciones realistas, escritorzuelos que creen en «la existencia de una realidad que retratar»

na Herrera, "Mitología chilota», Anales de la Universidad de Chile, año CVIII, tercer trimestre, 1950, 79, pp. 45-46). Es natural, por tanto, que el «imbuche» crezca mudo, ya que se le priva del comercio con otros seres humanos. Donoso adopta la leyenda del «imbuche» enfatizando la incapacidad de comunicación de la monstruosa criatura y llamando la atención al hecho de que al «imbuche» (como a Humberto Peñaloza) se le clausuran todas las posibilidades de apertura y acceso al mundo exterior. Respecto al «imbuche» afirma otro estudioso: «Los brujos tienen la costumbre de robar niños varones de seis meses a un año de edad, para hacerlos 'imbuches', lo cual realizan obstruyendo todos los agujeros naturales del cuerpo de las pequeñas víctimas" (Julio Vicuña Cifuentes, Mitos y supersticiones: Estudios del folklore chileno recogidos de la tradición oral, Santiago, Chile, Ed. Nascimento, 1974, 3. ${ }^{2}$ edición, pp. 80-84; subrayado del autor). La figura del «imbuche» y sus implicaciones simbólicas son centrales al mundo novelístico de José Donoso. Véase también Gloria Durán, «El obsceno pájaro de la noche: La dialéctica del chacal y del 'imbuche'», en Revista Iberoamericana, número 95, abril-junio de 1976, pp. 251-258. 
(p. 242; subrayado del autor); por el contrario, el auténtico escritor, privilegiado por la capacidad de "percibirlo todo» (p. 242), incursiona en «la realidad única» (p. 221) que yace potenciada en los abismos de la conciencia individual. La comarca que penetra el novelista es el espacio de la noche, el mundo al revés, el «otro lado» de lo establecido. Quijotismo siglo xx -después de Freud-, la odisea de este enajenado contemporáneo devela gigantes que, simultáneamente, son molinos y un sinnúmero vertiginoso de otridades. La ambigüedad del universo donosiano no apunta en dos, sino en múltiples direcciones: la bivocalidad cervantina se convierte en EOPN en la abigarrada polifonía de la descentralización que derrota al personaje y lo silencia definitivamente.

En efecto, mientras Don Quijote se reencuentra consigo mismo y con el orden establecido al reconocerse como Alonso Quijano, el Bueno, Mudito/Humberto se pierde en los alucinantes corredores de su fantasmagoría. Mientras el viejo manchego redescubre el centro que confiere sentido y justificación a su existencia, Humberto/Mudito se descentraliza totalmente, distanciándose del mundo establecido y de su "yo» original, aquella identidad falaz anterior a la imagen en el espejo. Tal ruptura con el mundo constituido, y en palabras de Jacques Derrida, «no puede anunciarse, presentarse, sino bajo el aspecto de la monstruosidad ${ }^{20}$. Bajo la máscara de un discurso monstruoso.

La ruptura con el mundo - la liberación de Eros, de Dionisio, de la alteridad - se manifiesta en Humberto en un aberrante anhelo de absoluto que es, simultáneamente, hambre de afirmarse y ser y hambre de descentralizarse y perecer. «Entonces, al mirarlo a usted, don Jerónimo, un boquete de hambre se abrió en mí y por él quise huir de mi propio cuerpo enclenque para incorporarme al cuerpo de ese hombre..., ser parte suya..., desgarrarlo, descuartizarlo, para apropiarme de todo lo suyo» (pp. 104-5). La desesperada nostalgia de la mirada de Humberto, para quien don Jerónimo encarna una heroicidad y una perfección caballeresca inexistentes en la realidad, se vuelve simultáneamente hacia una Inés de Azcoitía idealmente concebida, epítome de la belleza femenina. Al final de su odisea, el mismo Humberto hace alusión a una "Inés demasiado perfecta para que jamás haya existido» (p. 460); en otro lugar: "Inés no importa. La inventé yo para tocar la belleza, pero en el fondo de esa belleza de Inés habitabas tú, desde los siglos de los siglos, viva como las hogueras, variable como el agua» (p. 470). De la misma manera en que Peta Ponce habita en el fondo de la Inés ideal, un ser monstruoso se revela en lo hondo del heroico Azcoitía. Contemplando su tri-

${ }^{20}$ Derrida, De la gramatología, p. 10 (subrayado del autor). 
zada imagen en el estanque de la Rinconada, don Jerónimo descubre sus otros rostros: alteridad que lo subyuga y aniquila, y que no es sino la alteridad que subyuga y aniquila a Humberto, su creador.

El mutante escenario y los cambiantes personajes son pura fabulación: «Nada de esto existe, pero no puedo pensar en otra cosa que en estos monstruos» (p. 266). Las grotescas criaturas representan los disfraces con que el protagonista se disfraza para afirmarse ontológicamente, para ser alguien: «Si no nos disfrazamos de algo ... no somos nada" (p. 154). Irónicamente, el irresistible travestismo termina anulándolo: «Nada, nadie, no soy nada ni nadie» (p. 77). La noción de la nadería esencial de la existencia — del orden humano fatalmente arrasado por el caos- se pauta al final de la novela en la figura de la bruja (y de su perra) triunfantes ante el imbuchado personaje. El saco de yute que la vieja vacía de trapos y papeles - cifra del imbuchismo consumado que vacía al hombre de su virtualidad de ser- plasma la nihilista visión del mundo de Donoso. Existir entraña suspender el desgarrado diálogo: enmudecimiento que culmina con el silencio de la claudicación definitiva.

A diferencia del ideal discurso derridiano, en el que la descentralización y el desborde es exaltada celebración de vida, el discurso donosiano es exaltada convocación de muerte para el individuo. Al eterno retorno derridiano se contrapone la muerte sin renacimiento del mundo de Donoso: repetimos, muerte para el individuo, aunque eterno retorno para los textos infinitos con los que infinita e infructuosamente el hombre intenta nombrar y, a la par, justificar su truncada experiencia. Textos que hablan del afán humano por descifrar el sentido último de la existencia. Sentido eternamente diferido, para siempre postergado.

En este contexto, el silenciamiento del personaje nos conduce a otra interpretación del texto de Donoso, la cual nos ubica en el terreno de la problemática previamente mencionada: la de la despersonalización que arrebata al autor «real» de un texto determinado al entrar éste en el juego de la escritura plural de nuestra tradición. Si en el espacio ficcional de EOPN la voz de Humberto es la de Mudito, es la de Jerónimo, es la de la Peta, es la de Inés, y es incluso la voz silenciada de la última página, en el espacio «real» del mundo objetivo, la voz de José Donoso es la voz de todos y de cada uno de los lectores de su texto: voz que es todas las voces y ninguna, identidad que es todas las identidades y ninguna, en un tiempo que es todos los tiempos y ninguno, en un espacio que es todos los espacios y ninguno. La despersonalización del autor «real» instaura, por tanto, un cabal «lugar sin límites» en el que juegan el juego de la intertextualidad productora de sentido no sólo las dos productividades (la escritura y la lectura) que crean el espacio 
de una enunciación particular, sino, además, las productividades o textos o prácticas textuales que crean el espacio de nuestro horizonte cultural. Vasto escenario (que acoge el discurso de EOPN) y en el que cada texto - cada enunciación o escritura individual- deviene un mero trazo de esa escritura plural que es nuestra tradición.

Escritura que encarna la polifonía de la descentralización: juego de voces que se enfrentan, se interpenetran, se destruyen y reconstruyen en una dionisíaca fiesta de una infinita sustitución y de un eterno recurrir. Fiesta en la que las voces humanas individuales participan fugaz y desesperadamente ante la plena certeza de que para el hombre, inevitablemente, el resto es el silencio. Para la humanidad, sin embargo, el resto es la escritura plural, el inconcebible pluri-texto - terreno de todos y tierra de nadie- en que los trazos juegan su juego interminable: juego que evade el horizonte del ser (individual) pero que, sin embargo, bordea el sentido del ser: "Juego del trazo o de la 'différance' que no tiene sentido y que no existe. Que no pertenece a nadie» ${ }^{21}$, ya que, repetimos, pertenece a todos. A la larga, el enmudecimiento del protagonista de $E O P N$ devela un espacio que calladamente habla su eterna virtualidad, promesa de actualizaciones infinitas. Genotexto que perennemente opera su inagotable significación.

McGill University, Z. Nelly Martínez Montreal, Canadá.

${ }^{21}$ Derrida, «La différance», p. 72. 
